\title{
Deconsolidation of C/PEEK blanks: on the role of prepreg, blank manufacturing method and conditioning
}

\author{
T.K. Slange ${ }^{\mathrm{a}, \mathrm{b}}$, L.L. Warnet ${ }^{\mathrm{a}, *}$, W.J.B. Grouve ${ }^{\mathrm{a}}$, R. Akkerman ${ }^{\mathrm{a}, \mathrm{b}}$ \\ a Department of Mechanics of Solids, Surfaces and Systems (MS3), University of Twente, P.O. box 217, 7500 AE Enschede, The Netherlands \\ b ThermoPlastic composites Research Center (TPRC), P.O. box 770, 7500 AT Enschede, The Netherlands
}

\section{A R T I C L E I N F O}

\section{Keywords:}

B. Residual/internal stress

D. Moisture

E. Advanced fiber placement (AFP)

Deconsolidation

\begin{abstract}
A B S T R A C T
The combination of rapid automated lay-up and stamp forming has great potential for rapid manufacturing of lightweight load carrying components of thermoplastic composites. However, deconsolidation during blank heating is currently limiting the applicability of rapid lay-up blanks. This experimental work investigates the origin of deconsolidation in blanks produced by advanced fiber placement (AFP) versus traditional press consolidation. The influence of moisture on deconsolidation is investigated through deconsolidation experiments in a convection oven, as well as thermo-mechanical and residual gas analyses. The experiments revealed that thermal expansion of dissolved moisture is the main deconsolidation mechanism for press-consolidated blanks, but not for AFP blanks, which are suggested to deconsolidate mainly due to the release of frozen-in fiber stresses present in the used prepreg.
\end{abstract}

\section{Introduction}

Thermoplastic composites are increasingly being used in industry due to their advantages over thermoset composites. The advantages include a higher toughness, recyclability and their potential for automated high volume manufacturing due to their weldability and formability. For these reasons thermoplastic composites are well accepted in aerospace industry and, slowly but surely, also in automotive industry. However, the high demands from industry on performance and costs require both the advancement of existing and the development of new processing technologies, where the focus is on rapid and reliable manufacturing.

Stamp forming is a fine example of a well-established processing technology which uses the formability of thermoplastic composites at elevated temperatures to shape a flat laminate into a three dimensional component. Short cycle times can be achieved as no curing reaction is required, making the process very attractive for large series production. However, the application of stamp forming is currently limited to the production of secondary components with relatively simple geometries and uniform lay-up. Moreover, the blanks used to produce these components are usually cut from larger rectangular laminates, which are manufactured through time and energy consuming press or autoclave consolidation. Additionally, the cutting of blanks and trimming after stamp forming results in significant amounts of scrap material. Further advancement of the stamp forming technology is required to extend its application to structurally loaded primary components, increase weight savings and reduce costs.

The development of rapid automated lay-up technologies over the past decades, such as automated tape lay-up (ATL) and advanced fiber placement (AFP), offers the possibility for highly automated manufacturing of blanks with a high degree of lay-up freedom. This enables the use of tailored lay-ups, which can be optimized for their final application in terms of local thickness and fiber orientations. This allows for more efficient material use and weight reduction compared to traditional lay-ups. Moreover, near-net-shaped blanks can be produced, which reduces production scrap. For these reasons, the combination of rapid automated lay-up and stamp forming, as illustrated in Fig. 1, has the potential for a great step forward in the rapid manufacturing of load carrying components.

One of the current limitations of automated lay-up processes is that they do not provide the same level of blank consolidation as traditional press or autoclave consolidation due to the high lay-up rates that are required to achieve a high productivity. The consolidation quality of a blank is relevant, as it forms the basis for the consolidation quality of a component after stamp forming. The consolidation quality comprises several properties, such as void content and degree of interlaminar bonding, which determine the performance of a component [1-6]. These properties depend strongly on the local thermal and pressure

\footnotetext{
* Corresponding author.

E-mail address: 1.warnet@utwente.nl (L.L. Warnet).
} 


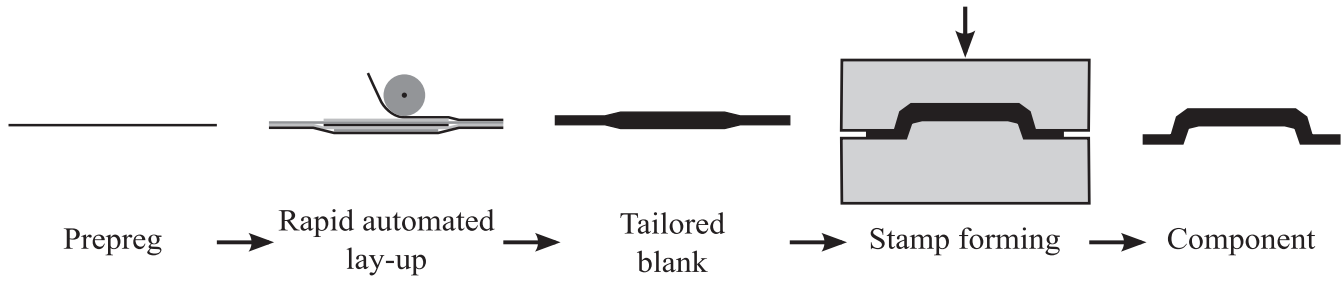

Fig. 1. Combination of rapid automated lay-up and stamp forming for components with tailored lay-ups. history. Due to the high cooling rates in the stamp forming process, there is limited time available for void elimination and interlaminar bonding. As a result, low blank consolidation quality, e.g. high void content and poor interlaminar bonding, could lead to poor component performance after stamp forming.

The degree of blank consolidation that can be achieved by automated lay-up technologies is depending on the process. Best results can be obtained with AFP, where narrow tapes are bonded together by continuous fusion bonding. However, achieving so-called full in-situ consolidation with AFP remains challenging, especially while maintaining a high productivity [7-11]. The latter is essential for the successful combination of rapid automated lay-up and stamp forming.

The potential of AFP as a blank manufacturing technology was explored by the authors in previous work [12]. The AFP blanks showed an inferior consolidation quality after stamp forming compared to pressconsolidated blanks. This was attributed to blank deconsolidation, which was found to be more pronounced for the AFP blanks. Deconsolidation is a common phenomenon during the processing of thermoplastic composites and plays a role in for example stamp forming [3,12-14], welding [15] and AFP [16]. It is often described as the lofting or debulking of a composite when being exposed to elevated temperatures (above melting temperature for semi-crystalline thermoplastics), especially when no external pressure is applied. During deconsolidation, voids form and grow within the composite and plies may even delaminate. Deconsolidation is often attributed to two primary causes. Firstly, the release of stresses carried by the fiber bed, which were introduced during manufacturing of the laminate, has been identified as source of deconsolidation by many authors [14,15,17-23]. However, the materials used in these works were mainly woven fabrics. These can store a large amount of elastic energy due to the undulating fiber bundles. The effect is less pronounced for unidirectional pregreg, as this undulation is not present and hence less elastic energy is stored in the fiber bed [24]. Secondly, a well known source of deconsolidation is the thermal expansion of dissolved gas [25] and moisture $[15,21,26,27]$ in the matrix, especially at high heating rates. Deconsolidation can easily be prevented by applying external pressure during heating $[15,20,28]$. However, this requires contact between composite and tooling. For some technologies, including stamp forming, it is preferred to use contact-less heating methods, such as IR heater panels. In this case, deconsolidation cannot be prevented by applying external pressure. As a result, a blank may deconsolidate during the heating phase of the stamp forming process, as is schematically shown in Fig. 2.

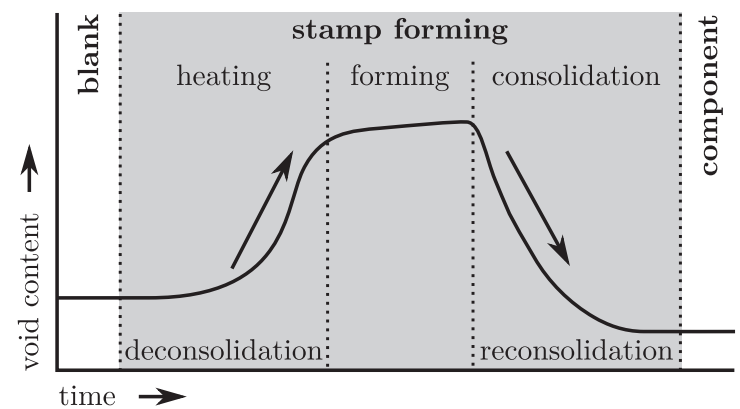

Fig. 2. Typical void evolution during the three stages of the stamp forming process.
The voids formed by deconsolidation have to be eliminated again during reconsolidation, making the consolidation process somewhat inefficient. Deconsolidation may even lead to poorly consolidated parts if reconsolidation is insufficient. Additionally, deconsolidation obstructs heat transfer in the blank, increasing the required heating time in the IR oven $[12,13]$.

The current paper aims to investigate the deconsolidation mechanisms that cause the previously observed [12] differences in deconsolidation behavior between blanks produced by press-consolidation and AFP. Proper characterization of the deconsolidation behavior could lead to methods to reduce or prevent it. Controlling deconsolidation is thought to be essential for improving consolidation quality of stamp formed components, especially for blanks produced by rapid AFP technologies.

In this work the deconsolidation behavior of blanks is characterized experimentally. Blanks produced both by press-consolidation and AFP, aimed at rapid lay-up, are considered, in order to investigate the influence of blank consolidation quality and production method on deconsolidation behavior. As moisture expansion has been identified as the most likely deconsolidation mechanism, this work focuses on the effect of dissolved moisture on deconsolidation. The release of fiber bed stresses is assumed to be less dominant due to the use of unidirectional tapes. Various treatments are applied in order to alter the moisture content of the blanks prior to deconsolidation in a convection oven. Deconsolidation is characterized by thickness measurements and crosssectional micrographs, while moisture content is measured through weight loss. Additional thermo mechanical (TMA) and residual gas analyses (RGA) are performed in order to identify a relation between thickness increase due to void formation and moisture release.

\section{Experimental work}

\subsection{Materials and blank manufacturing}

Cross-ply $[0 / 90]_{4 \mathrm{~s}}$ laminates were prepared from unidirectional (UD) TenCate Cetex ${ }^{\circledast}$ TC1200 AS4/PEEK prepreg material according to the procedures listed below. This prepreg has a listed consolidated ply thickness and fiber volume fraction after press consolidation of $0.15 \mathrm{~mm}$ and $59 \%$, respectively, and a very low $(<1 \%)$ void content [29]. The glass transition temperature $T_{\mathrm{g}}$ and melting temperature $T_{\mathrm{m}}$ are $143^{\circ} \mathrm{C}$ and $343^{\circ} \mathrm{C}$, respectively. C/PEEK is known for its low moisture uptake (between 0.1 and $0.2 \%$, depending on conditions [30-32]) and the limited effect of moisture on mechanical properties $[31,32]$.

- Press consolidation. A $600 \times 600 \mathrm{~mm}^{2}$ laminate was laid up by hand from 6 in. wide prepreg. The laminate was placed between $1 \mathrm{~mm}$ stainless steel caul sheets coated with Marbocote 227 CEE release agent and consolidated in a $200 \mathrm{t}$ Pinette P.E.I. press with a 20 min dwell at $386^{\circ} \mathrm{C}$ and 10 bars and cooled at a rate of $2.5^{\circ} \mathrm{C} /$ min. This procedure results in a void-free laminate.

- AFP. A Coriolis Composites AFP robot with laser heating was used to produce a $330 \times 330 \mathrm{~mm}^{2}$ laminate from $1 / 4$ in. wide prepreg at a rate of $200 \mathrm{~mm} / \mathrm{s}$ and a nip-point temperature of approximately $450{ }^{\circ} \mathrm{C}$ (measured by thermal camera). A compaction force of $100 \mathrm{~N}$ was applied by a deformable silicon roller of $40 \mathrm{SH}$ hardness, 
Table 1

Secondary treatments prior to deconsolidation.

\begin{tabular}{|c|c|c|c|}
\hline Treatment & Method & Conditions & Duration \\
\hline AS & Ambient storage & $\begin{array}{c}\mathrm{Lab} \\
\left(\approx 23^{\circ} \mathrm{C} / 50 \% \mathrm{RH}\right)\end{array}$ & 2 months \\
\hline vos & Vacuum oven storage & $70^{\circ} \mathrm{C} /$ vacuum & 2 months \\
\hline HCS & $\begin{array}{c}\text { Humidity chamber } \\
\text { storage }\end{array}$ & $80{ }^{\circ} \mathrm{C} / 85 \% \mathrm{RH}$ & 2 weeks \\
\hline HT-3H@150C & Heat treatment & $150^{\circ} \mathrm{C}$ & $3 \mathrm{~h}$ \\
\hline HT-15M@250C & Heat treatment & $250^{\circ} \mathrm{C}$ & $15 \mathrm{~min}$ \\
\hline HT-3H@250C & Heat treatment & $250^{\circ} \mathrm{C}$ & $3 \mathrm{~h}$ \\
\hline HT-3H@250C+HCS & $\begin{array}{c}\text { Heat } \\
\text { treatment }+ \text { Humidity } \\
\text { chamber storage }\end{array}$ & $\begin{array}{c}250{ }^{\circ} \mathrm{C}+80^{\circ} \mathrm{C} / \\
85 \% \mathrm{RH}\end{array}$ & $3 h+5$ days \\
\hline
\end{tabular}

resulting in an compaction pressure of approximately $1 \mathrm{bar}$. This procedure results in a laminate which is not void-free and has imperfect interlaminar bonding, as is typical for blanks produced at high lay-up rates.

\subsection{Oven deconsolidation experiments}

\subsubsection{Pretreatments}

The laminates were given a primary treatment at ambient lab conditions $\left(\approx 23^{\circ} \mathrm{C} / 50 \% \mathrm{RH}\right)$ for 2 months prior to cutting them into smaller $100 \times 100 \mathrm{~mm}^{2}$ specimens. This simulates long term laminate storage between blank manufacturing and stamp forming and results in blanks which are saturated with moisture at ambient conditions. The subsequent secondary treatments are listed in Table 1 , and include treatments that further alter the moisture content by drying or humidifying. Additionally, various high temperature (above $T_{\mathrm{g}}$ ) heat treatments in a convection oven were included to investigate the effect of treatment temperature and duration. Relaxation of residual stresses and additional crystallization may occur at these temperatures [33], but further analysis of this is not considered within the scope of this work.

A total of three specimens were tested per pretreatment. The pressconsolidated specimens were subjected to all pretreatments, while the AFP specimens were only subjected to three treatments based on the results of the press-consolidated specimens; ambient storage (AS), vacuum oven storage (VOS) and one heat treatment (HT-3H@250C). The specimens were weighed regularly on a semi-micro balance in order to monitor the moisture content during the treatments. It was assumed that saturation was reached once no further significant weight change was observed over a period of one week.

\subsubsection{Deconsolidation treatment}

All specimens were deconsolidated within $1 \mathrm{~h}$ after finishing the pretreatment by heating them in a preheated convection oven at $390{ }^{\circ} \mathrm{C}$ for $20 \mathrm{~min}$. This is a typical preheating temperature for C/PEEK blanks during stamp forming.Temperature measurements have shown that the laminates experience a similar heating curve during heating in the convection oven and heating in an IR oven during stamp forming. This can be seen in Fig. 3, which shows the core and surface temperature measured by thermocouples during the deconsolidation cycle and a typical stamp forming cycle. The specimens were held in the oven for 20 min to ensure full deconsolidation [20] and cooled to room temperature by natural convection. The effect of gravity on deconsolidation was eliminated by hanging the specimens vertically using alligator clips.

\subsubsection{Characterization}

The relative thickness increase after heat treatment of a specimen gives a quantitative measure for the amount of deconsolidation. In case the specimen is initially void-free, the relative thickness increase also gives an estimate of the void content:

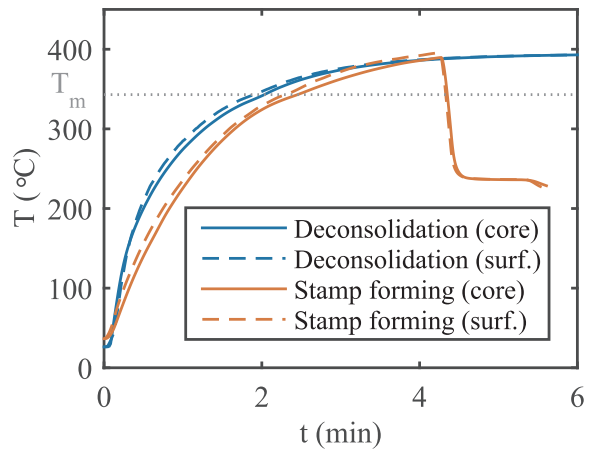

Fig. 3. Core and surface temperature measured by thermocouples during the deconsolidation cycle (convection oven) and a typical C/PEEK stamp forming cycle (IR oven). (For interpretation of the references to color in this figure legend, the reader is referred to the web version of this article.)

$v_{\mathrm{v}} \approx h=\frac{H_{1}-H_{0}}{H_{0}} \times 100 \%$

Here, $v_{\mathrm{v}}$ is the void content per unit volume, $h$ the relative thickness increase, $H_{0}$ the thickness before deconsolidation and $H_{1}$ the thickness after deconsolidation. The thickness of each specimen was measured at 5 predefined points just before and after the deconsolidation treatment using a micrometer. Additionally, the void content was characterized qualitatively through cross-sectional micrographs of the specimens.

In case all moisture is removed from the composite during the deconsolidation treatment and no additional weight loss is caused by other phenomena, the moisture content prior to the deconsolidation treatment can be estimated based on the relative weight loss:

$w_{\mathrm{m}} \approx w=\frac{W_{0}-W_{1}}{W_{1}} \times 100 \%$

Here, $w_{\mathrm{m}}$ is the moisture content per unit weight prior to deconsolidation, $w$ the relative weight loss during deconsolidation, $W_{0}$ the weight before deconsolidation and $W_{1}$ the weight after deconsolidation. Each specimen was weighed using a semi-micro balance $(0.01 \mathrm{mg}$ precision) just before and after the deconsolidation treatment.

\subsection{TMA and RGA experiments}

The deconsolidation behavior was further analyzed by performing continuous measurements of thickness increase and moisture release during deconsolidation through zero-force thermo-mechanical analysis (TMA) and residual gas analysis (RGA), respectively. The TMA anlyses were performed on a Mettler Toledo TMA/SDTA840. The relative thickness increase measured during TMA is a combination of thermal expansion, crystallization effects and deconsolidation. The release of moisture molecules was detected by measuring the ion current for $m / z=18$ for $\mathrm{H}_{2} \mathrm{O}$ during the RGA in a Netsch STA 449 F3.

Small $8 \times 8 \mathrm{~mm}^{2}$ specimens were cut from the press-consolidated and AFP laminates that were stored at ambient conditions. The specimens were heated inside the test equipment following the thermal profiles shown in Fig. 4. The profiles includes either only a deconsolidation cycle (D), or an additional preceding heat treatment cycle (HT) of $3 \mathrm{~h}$ at $250^{\circ} \mathrm{C}$. Heating and cooling rates were set to $20^{\circ} \mathrm{C} / \mathrm{min}$ in order avoid large temperature gradients within the specimens. Both the TMA and RGA were performed under nitrogen atmosphere to prevent degradation of the polymer. An negligible external pressure of $1.5 \mathrm{kPa}$ was applied during the TMA to ensure contact with the specimen. 


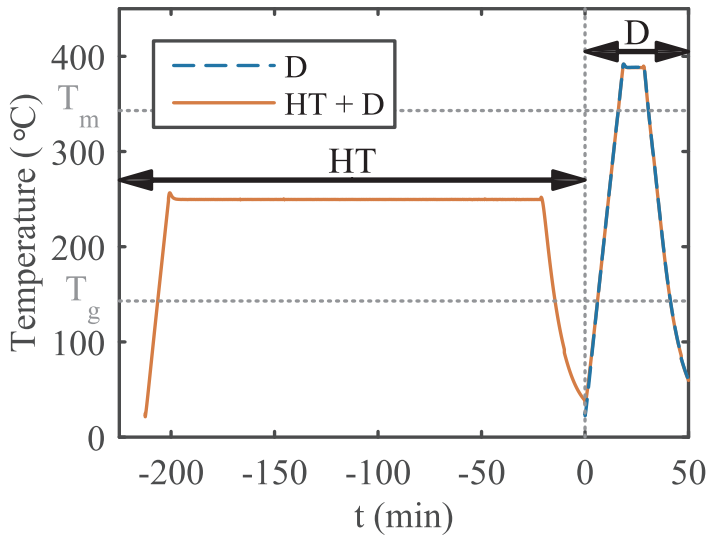

Fig. 4. Measured temperature during the TMA for a deconsolidation cycle (D) and a cycle with additional heat treatment prior to deconsolidation (HT $+\mathrm{D})$. (For interpretation of the references to color in this figure legend, the reader is referred to the web version of this article.)

\section{Results}

\subsection{Oven deconsolidation experiments}

\subsubsection{Press-consolidated specimens}

Fig. 5 shows the average relative thickness increase versus the relative weight loss during deconsolidation for the press-consolidated specimens. The measurements can be divided into two groups, indicated by the dotted lines in Fig. 5 .

On the one hand, there is a large group of treatments (AS, HCS, HT3H@150C, HT-15M@250C and HT-3H@250C+HCS) where weight loss differs among the treatments, but thickness increase does not change significantly and remains at $12-15 \%$, indicating that deconsolidation behavior is not sensitive to moisture content in this group. The group includes all treatments which show a weight loss of $0.06 \%$ and more during deconsolidation. The ambient stored (AS) specimens show a weight loss of $0.08 \%$, which is consistent with the saturation level found literature [30-32].

On the other hand, there is a group of two treatments (VOS and HT$3 \mathrm{H} @ 250 \mathrm{C}$ ) which show a weight loss of less than $0.03 \%$ and a significant reduction in thickness increase to less than $5 \%$. This indicates a more effective reduction in moisture content by these treatments and a much higher sensitivity of deconsolidation to moisture content compared to the other group of treatments.

The heat treatment for $3 \mathrm{~h}$ at $250{ }^{\circ} \mathrm{C}$ (HT-3H@250C) is most effective in reducing both moisture content and deconsolidation to $0.01 \%$ and 1.5\%, respectively. The shorter heat treatment (HT-15M@250C) and lower temperature heat treatment (HT-3H@150C) have only

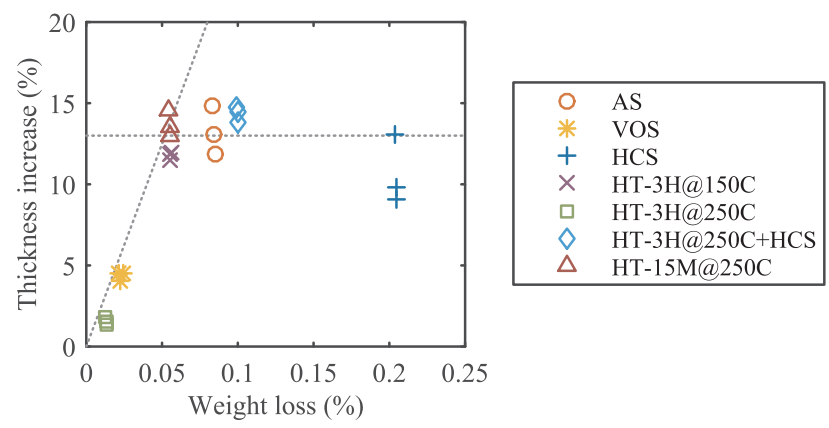

Fig. 5. Thickness increase vs. weight loss during deconsolidation for pressconsolidated specimens. AS = ambient storage, VOS = vacuum oven storage, HCS = humidity chamber storage and HT = heat treatment. (For interpretation of the references to color in this figure legend, the reader is referred to the web version of this article.) slightly reduced the moisture content, while not affecting deconsolidation significantly. Rehumidifying a heat treated specimen (HT-3H@ $250 \mathrm{C}+\mathrm{HCS}$ ) restored all deconsolidation. This also indicates that annealing of the matrix or further crystallization during the heat treatments did not influence the deconsolidation behavior. The heat treatments can therefore in this case simply be considered as high temperature drying treatments.

The thickness measurements are further supported by cross-sectional micrographs, which are shown in Fig. 6. While a specimen before deconsolidation is void-free, the deconsolidated specimens show more voids for increasing thickness increase. The voids are mainly found at the interfaces between the plies, i.e. interlaminar voids, while the plies have remained mostly intact. Similar deconsolidated states were found for the group of specimens with $12-15 \%$ thickness increase. Fig. 6(b) shows that interlaminar voids have formed delaminations, which could also be observed as blisters on the surface of the specimens. The specimens stored in the vacuum oven (VOS, Fig. 6(c)) show much less interlaminar voids and no delaminations. The voids are mainly located between the plies closest to the mid-plane. The specimens that were exposed to a heat treatment (HT-3H@250C, Fig. 6(d)) show an almost void-free cross-section. This matches the minimal thickness increase of $1.5 \%$ for these specimens.

\subsubsection{AFP specimens}

The average relative thickness increase versus the relative weight loss after deconsolidation is shown in Fig. 7 for the AFP specimens. The AFP specimens show a similar plateau as the press-consolidated specimens where thickness increase is not related to weight loss, indicated by the dotted line. However, the observed weight loss and thickness increases are much higher for the AFP specimens compared to the pressconsolidated specimens. The AFP specimens stored at ambient conditions (AS) show a weight loss of approximately $0.3 \%$, three times higher than the press-consolidated specimens and also higher than the saturated moisture content reported in literature [30-32]. Possibly additional moisture was entrapped in voids between the plies. The thickness increase is approximately $60 \%$, about four times higher. Both the vacuum oven treatment (VOS), as well as the heat treatment for $3 \mathrm{~h}$ at $250{ }^{\circ} \mathrm{C}$ (HT-3H@250C), have not significantly affected thickness increase. This is in contrast with the press-consolidated specimens, where these treatments were very effective in reducing deconsolidation. However, a large weight loss was still observed after deconsolidation for both treatments. This could indicate that the treatments did not eliminate all moisture prior to deconsolidation or that additional volatiles are released during deconsolidation.

A cross-sectional micrograph of a deconsolidated AFP specimen is compared to a specimen before deconsolidation in Fig. 8. The crosssection of the deconsolidated specimen confirms the larger amount of deconsolidation of the AFP specimens. Plies have almost completely debonded. This is not surprising, given the limited interlaminar bonding of the specimen prior to deconsolidation due to the high lay-up rate during AFP. Besides debonding, the plies themselves also show signs of deconsolidation, as if individual fibers or small bundles of fibers have popped out from the plies, forming rough ply surfaces with loose fibers. This was not observed for the press-consolidated specimens. Moreover, the AFP specimens showed significant local out-of-plane ply waviness instead of the large blisters observed for the press-consolidated specimens.

\subsection{TMA and RGA experiments}

\subsubsection{Heat treatment}

The results of the TMA and RGA during the heat treatment (HT) part of HT + D cycle are shown in Fig. 9(a) and (b), respectively, for the press-consolidated and AFP specimens. The TMA curves show an expansion upon heating to the plateau at $250^{\circ} \mathrm{C}$ of up to $2 \%$ for the pressconsolidated specimen. The original thickness is restored for both 


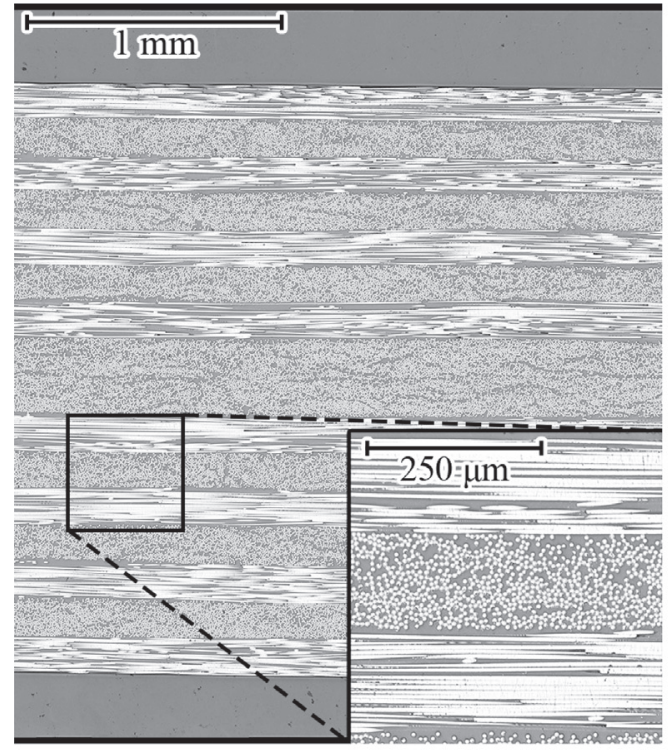

(a) Before deconsolidation

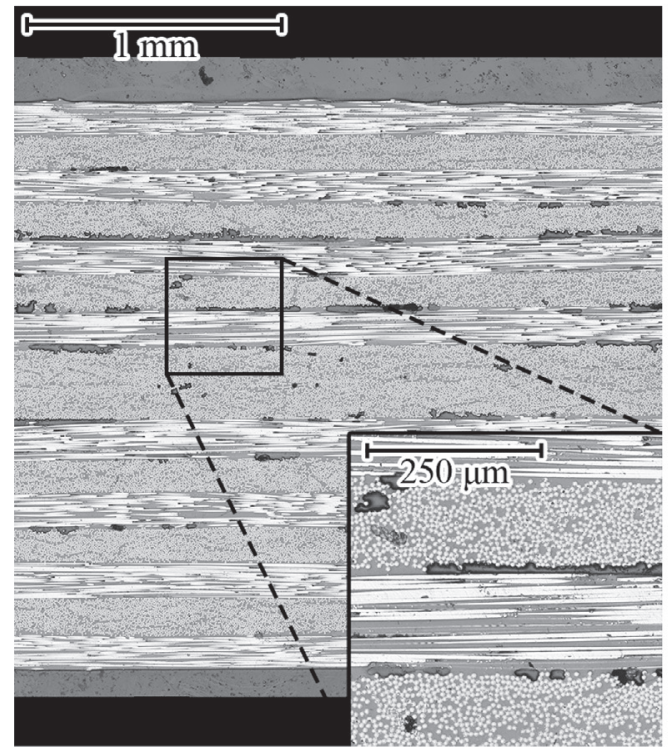

(c) Deconsolidated, VOS $(h=4.4 \%)$

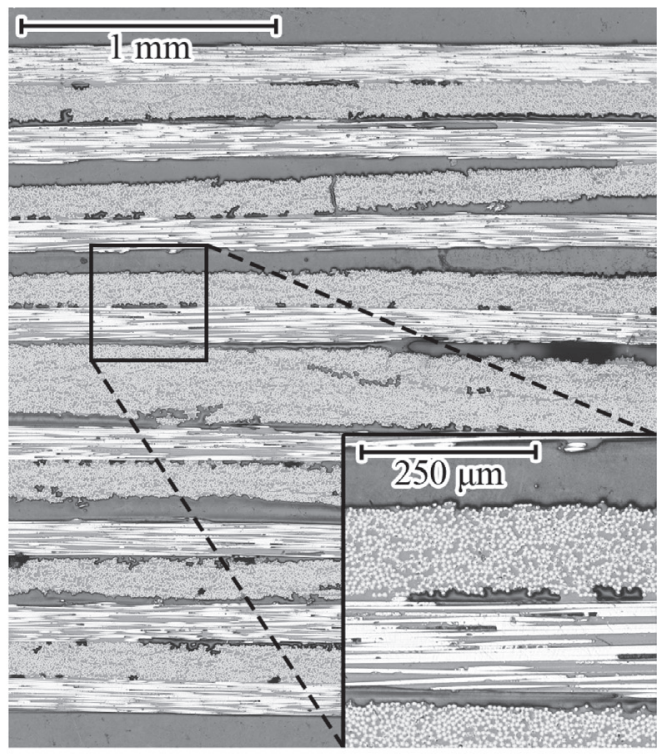

(b) Deconsolitaded, AS $(h=13.3 \%)$

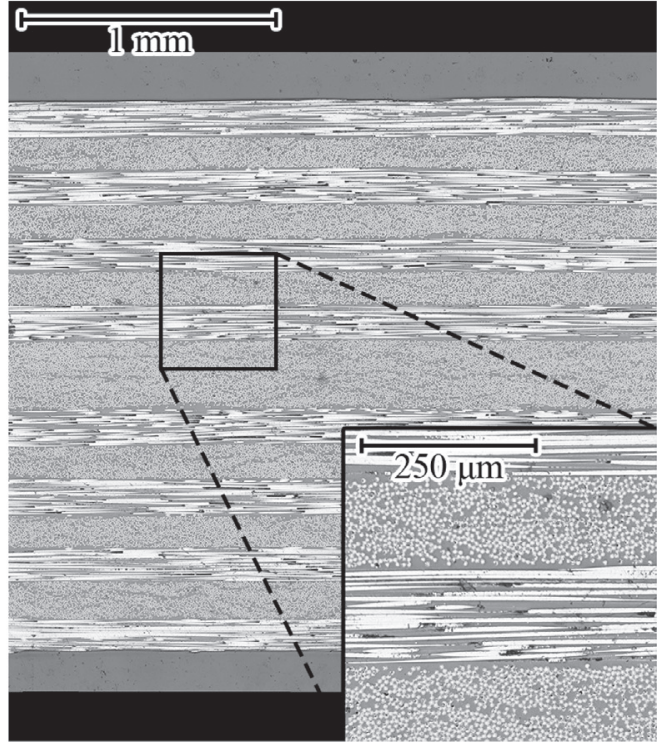

(d) Deconsolidated,

HT-3H@250C

$(h=1.5 \%)$

Fig. 6. Micrographs of cross-sections of press-consolidated specimens (a) before deconsolidation, and (b) after ambient storage (AS), (c) vacuum oven storage (VOS) and (d) heat treatment (HT-3H@250C), each followed by deconsolidation.

specimens upon cooling, indicating that only reversible thermal expansion has occurred and no deconsolidation. Moreover, the lack of crystallization shrinkage for both specimens indicate that both specimens had similar high crystallinity. The increase in ion current in the RGA curve above the baseline level of $2 \cdot 10^{-11} \mathrm{~A}$ confirms that moisture is released during the heat treatment. A large peak in the current is observed when crossing $T_{\mathrm{g}}$ at $-204 \mathrm{~min}$. This is followed by a gradually decreasing current during the dwell at $250{ }^{\circ} \mathrm{C}$ until a stable level is reached after about $150 \mathrm{~min}$. This time is most likely sensitive to the specimen dimensions, as moisture diffusion will occur both in-plane and through thickness. The peak is also larger for the AFP specimen, confirming that the AFP specimen contained more moisture than the press-consolidated specimen.

\subsubsection{Deconsolidation - press-consolidated specimens}

The results of the TMA during the deconsolidation (D) part of both treatments for the press-consolidated specimens are shown in Fig. 10(a) and (b). Initially, both specimens show an identical expansion curve. However, a major difference appears when the melting temperature is approached during heat-up. At this point, the specimen without heat treatment shows a sudden drastic increase in thickness in just a few seconds. This is followed by a gradual decrease in thickness over a period of approximately $1 \mathrm{~min}$. This confirms that deconsolidation occurs very rapidly and that it completed well within the cycle of $20 \mathrm{~min}$. The sudden increase in thickness around $T_{\mathrm{m}}$ is accompanied by a sudden increase in ion current, as is shown in the RGA curve in Fig. 10(c). The moisture release had already started to increase above $T_{\mathrm{g}}$. The current drops back to its initial level after the peak. 


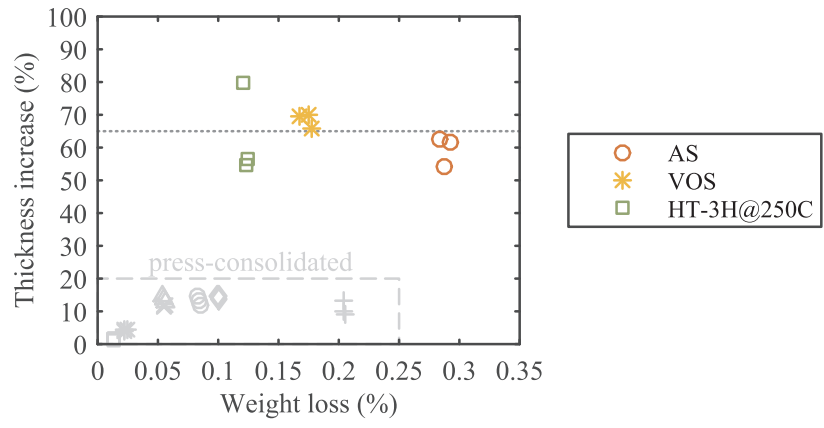

Fig. 7. Thickness increase vs. weight loss during deconsolidation for AFP specimens. AS = ambient storage, VOS = vacuum oven storage and HT = heat treatment. (For interpretation of the references to color in this figure legend, the reader is referred to the web version of this article.)

The heat treated specimen does not show this deconsolidation peak and the ion current remains constant during the deconsolidation cycle. This indicates that almost no moisture is released and confirms that the heat treatment has removed nearly all moisture. No thickness increase is observed for this specimen at the end of the cycle, as also was the case in the oven deconsolidation experiments. This also indicates that only reversible thermal expansion took place for this specimen.

\subsubsection{Deconsolidation - AFP specimens}

The results of the TMA and RGA during the deconsolidation (D) part of both treatments are shown in Fig. 11 for the AFP specimens. Clearly, both the TMA and RGA curves are very different from the press-consolidated specimens. The AFP specimens do not show the sudden expansion peak that was found in the TMA results for the press-consolidated specimen without heat treatment. Instead, both specimens show a more gradual expansion when approaching the melting

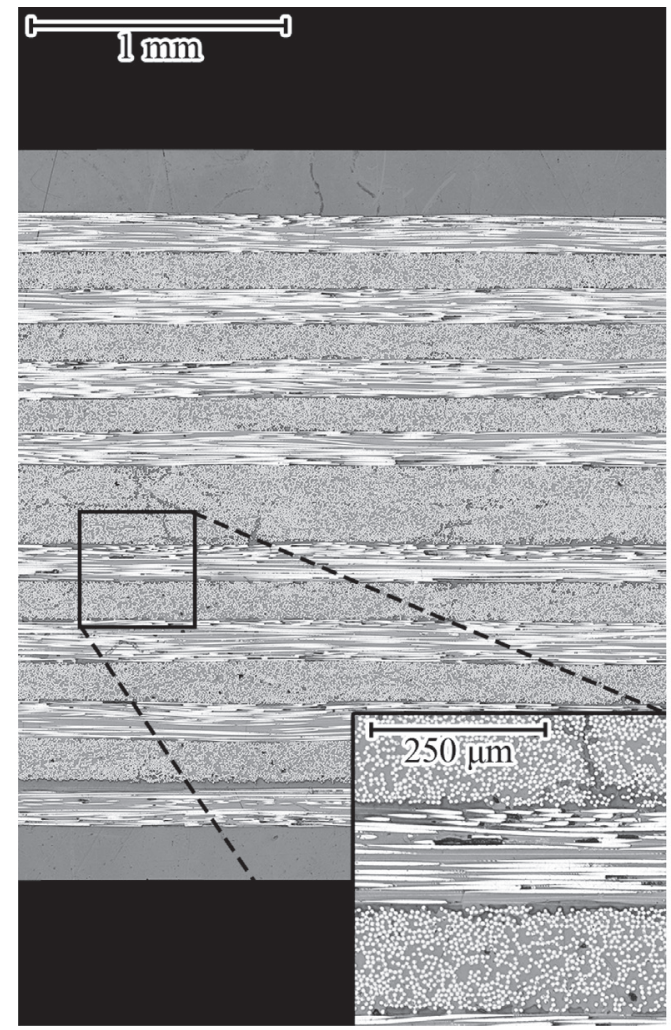

(a) Before deconsolidation temperature, followed by only very limited sagging. The heat treatment did not affect the deconsolidation behavior of the AFP specimen, as both specimens show exactly the same expansion curve. Moreover, the AFP specimens show a larger thickness increase compared to the pressconsolidated specimen without heat treatment. This is consistent with the results of the oven deconsolidation experiments.

Although the heat treatment did not affect deconsolidation behavior, the effect is visible in the RGA curves. The specimen without heat treatment shows an early increase in ion current near $T_{\mathrm{g}}$. This peak was not present for the press-consolidated specimen. A second peak appears around the melting temperature, but this peak is much lower and wider, and occurs later than for the press-consolidated specimen. The heattreated specimen shows a small increase in ion current from the heat treatment temperature of $250{ }^{\circ} \mathrm{C}$ to beyond the melting temperature, indicating that not all moisture was removed from the AFP specimen during the heat treatment.

Besides the release of moisture, the release of other ion fragments $(\mathrm{m} / \mathrm{z}=14,16,20,28,29,32,36,38,40,44)$ was also detected during the RGA of AFP specimens. These fragments correspond with the constituents of air, i.e. $\mathrm{N}_{2}, \mathrm{O}_{2}, \mathrm{Ar}$ and $\mathrm{CO}_{2}$, which was most likely entrapped in voids between the plies. No release of air was observed for the press-consolidated specimens. This additional release of air may also explain the larger weight loss that was observed for AFP specimens in the oven deconsolidation experiments.

\section{Discussion}

The oven deconsolidation experiments, as well as the TMA and RGA, showed clear differences between the deconsolidation behavior of press-consolidated and AFP specimens and their response to the pretreatments. While the press-consolidated specimens showed mainly interlaminar voids and reduced deconsolidation for two of the treatments, the AFP specimens showed both inter and intralaminar voids

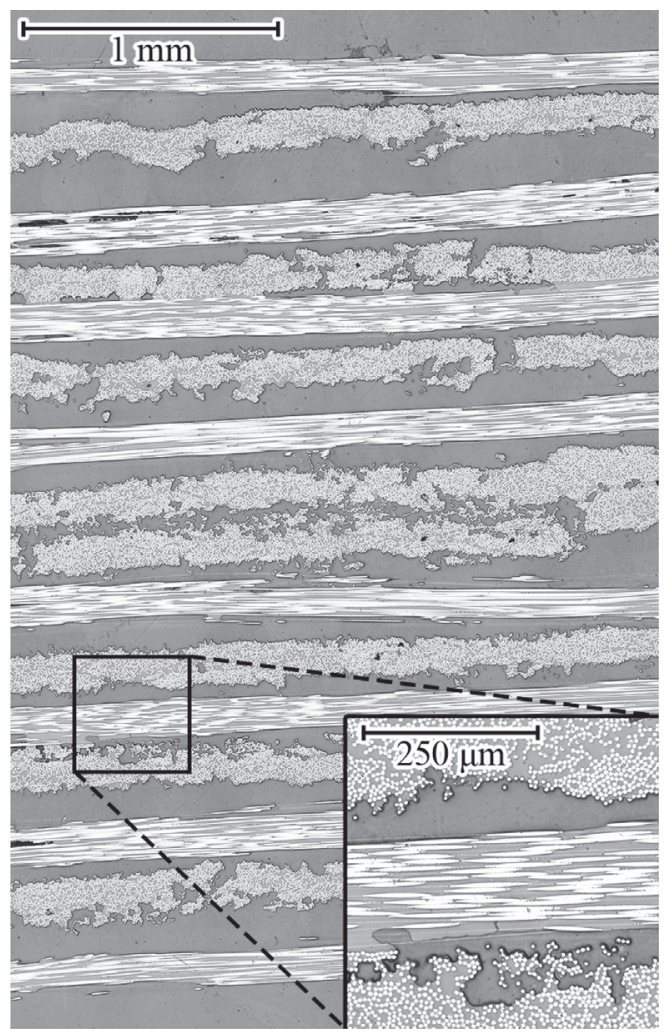

(b) Deconsolidated, AS $(h=59.5 \%)$

Fig. 8. Micrographs of cross-sections of AFP specimens (a) before deconsolidation and (b) after ambient storage (AS) followed by deconsolidation. 


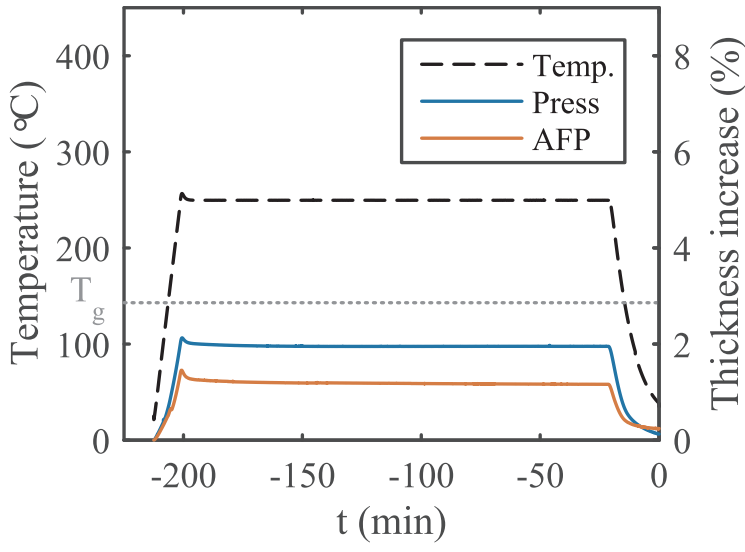

(a) TMA

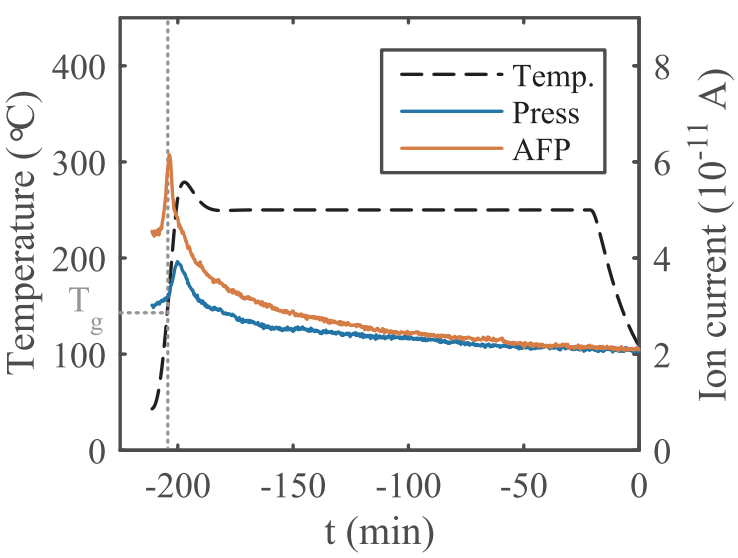

(b) RGA

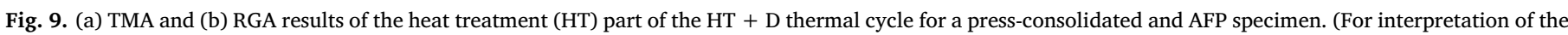
references to color in this figure legend, the reader is referred to the web version of this article.)

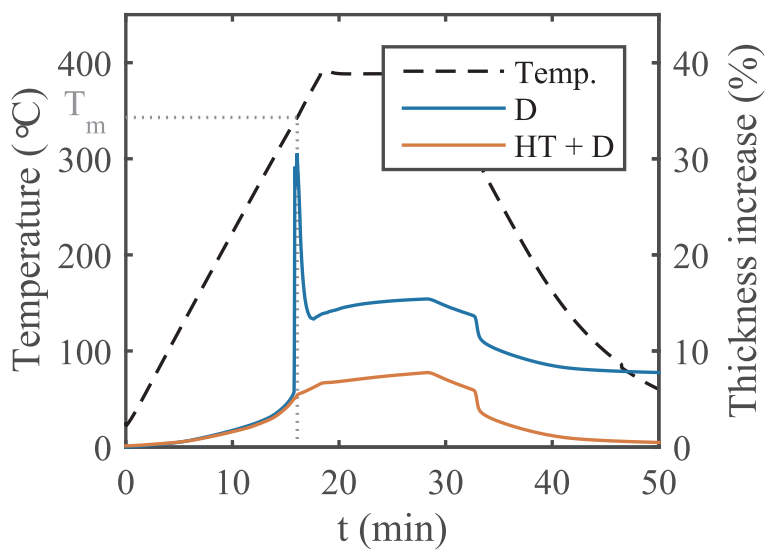

(a) TMA

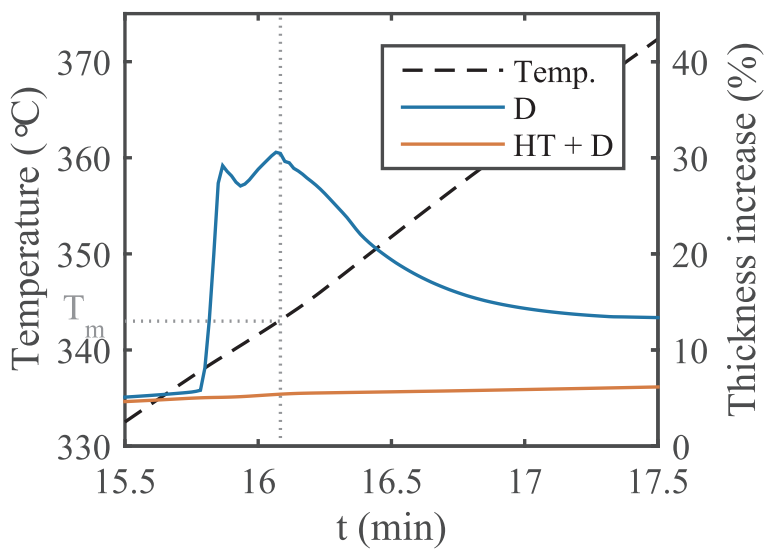

(b) TMA - zoomed in

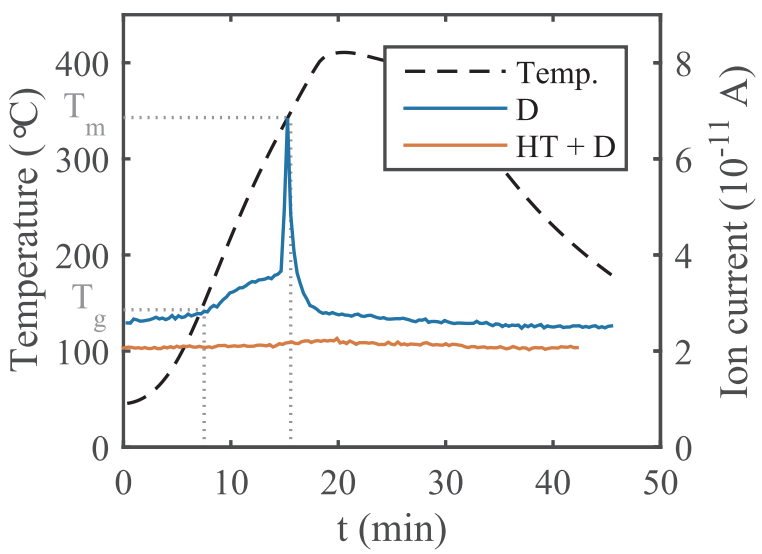

(c) RGA

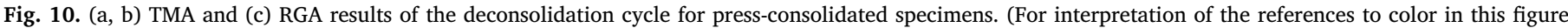
legend, the reader is referred to the web version of this article.)

and ply roughening and no influence of the treatments. The following sections discuss the origin of these differences.

\subsection{Influence of moisture}

The press-consolidated specimens showed a high sensitivity of thickness increase to weight loss at low weight loss. Additionally, the TMA and RGA experiments showed a correlation between thickness increase and moisture release. This suggests that deconsolidation in press-consolidated laminates is indeed dominated by the formation of voids due to the thermal expansion of moisture that is dissolved in the matrix of the composite material. This is supported by the fact that a 


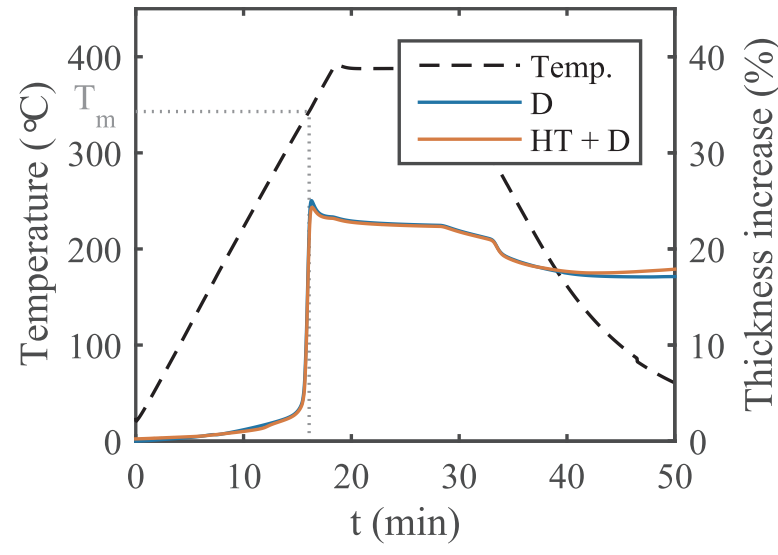

(a) TMA

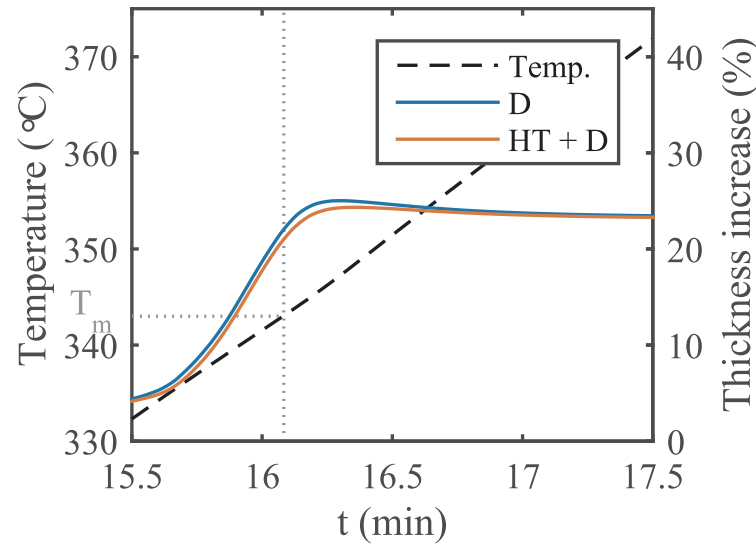

(b) TMA - zoomed in

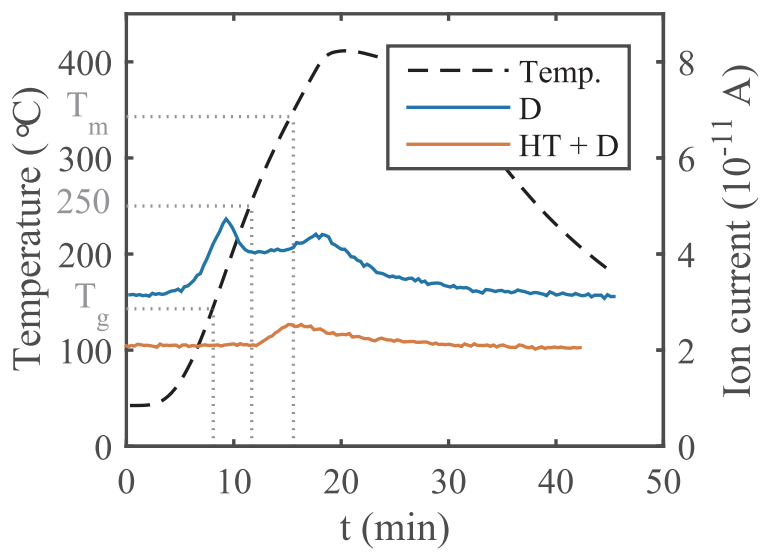

(c) RGA

Fig. 11. (a, b) TMA and (c) RGA results of the deconsolidation cycle for AFP specimens. (For interpretation of the references to color in this figure legend, the reader is referred to the web version of this article.)

heat treatment was able to eliminate all moisture and deconsolidation, and that rehumidifying such heat treated specimens restored deconsolidation.

With this knowledge, a phenomenological explanation of the TMA and RGA curves of the press-consolidated specimen can now be proposed. A schematic representation of the deconsolidation process is shown in Fig. 12. (i) The composite contains dissolved moisture. (ii) An increase in temperature causes the water molecules (blue) to diffuse through the composite, as well as to the surroundings. This process is accelerated above $T_{\mathrm{g}}$, due to the increased polymer chain mobility. Voids start to nucleate at the interfaces between the plies. At these locations there is a drastic pressure build-up due to the hot water vapor. (iii) Once the melting temperature is reached, the matrix softens and the composite can no longer withstand the internal pressure of the voids. The voids expand to reduce their internal pressure and cause a sudden increase in thickness. (iv) As the voids grow, they can merge and form void channels at the interfaces between the plies [21,27]. These channels can eventually reach to the edges of the specimen if sufficient voids are formed. At this point, the internal void pressure is further reduced and the water vapor is released to the surroundings, explaining the moisture release peak in the RGA that accompanies the sudden expansion measured in the TMA. (v) As the internal void pressure is now relieved, the specimen can sag in order to relax stresses induced in the composite by the internal void pressure, explaining the thickness reduction after deconsolidation. This also explains the plateau in Fig. 5 at higher moisture contents, as all these specimens have sagged

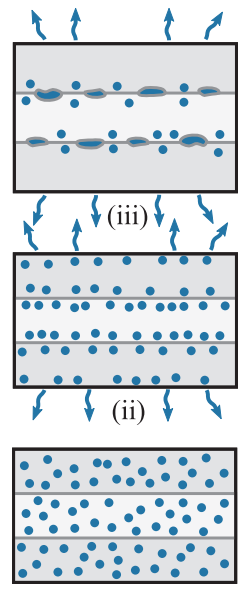

(i)

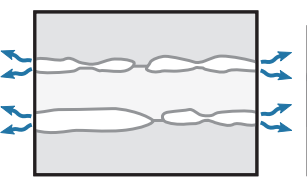

(iv)

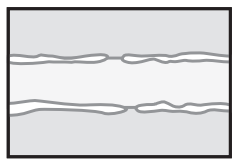

(v)

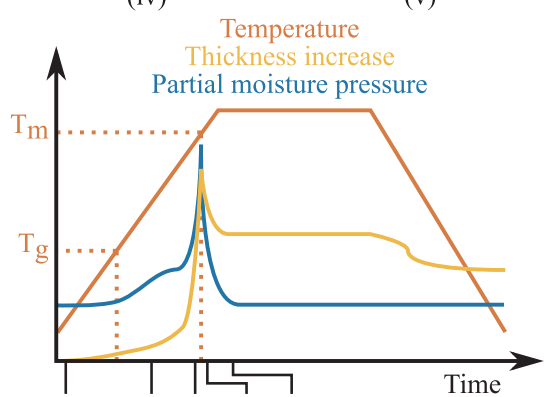

(i) (ii) (iii) (iv) (v)
Fig. 12. Schematic representation of the deconsolidation process due to moisture (in blue) expansion. (For interpretation of the references to color in this figure legend, the reader is referred to the web version of this article.)

back to a similar thickness.

The press-consolidated specimen subjected to the heat treatment did not show any deconsolidation due to its low moisture content. Instead, all thickness increase during the deconsolidation cycle of the heat- 


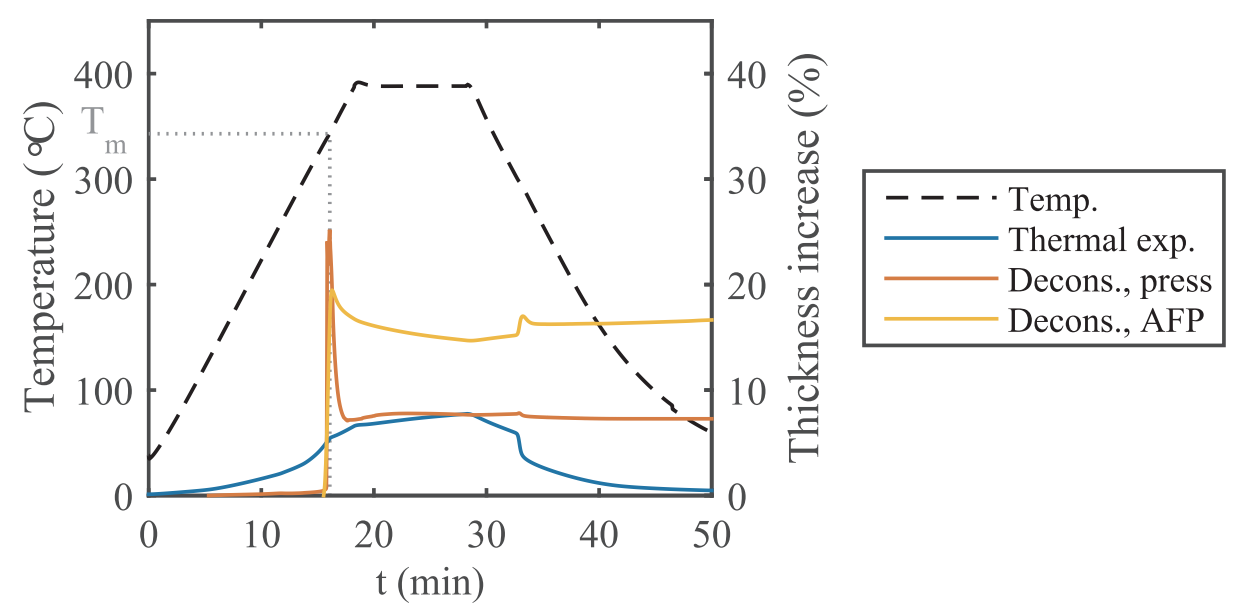

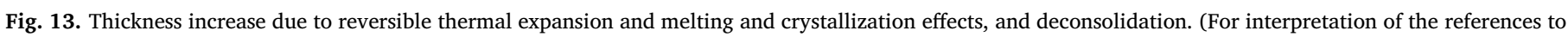
color in this figure legend, the reader is referred to the web version of this article.)

treated specimen can be attributed to reversible thermal expansion and melting and crystallization effects. The net thickness increase due to deconsolidation can now be found by subtracting the thermal expansion from the total thickness increase of the untreated specimen, as is shown in Fig. 13. The curve confirms that deconsolidation of the press-consolidated specimen occurs almost instantaneously, i.e. in less than $10 \mathrm{~s}$, when crossing the melting temperature. This is followed by some subsequent gradual sagging and a steady thickness is achieved within two to four minutes after reaching $T_{\mathrm{m}}$.

The results demonstrate that dissolved moisture can be a major issue in processing of thermoplastic composites. This is even the case for $\mathrm{C}$ / PEEK, although its low moisture uptake and limited knockdown of mechanical properties by moisture are often used as a selling point $[31,32]$. Low moisture levels reached under ambient storage conditions can already cause significant deconsolidation. Therefore, removing this moisture is essential in order to avoid deconsolidation during processing. Low temperature vacuum oven storage and a high temperature heat treatment were the most effective treatments tested in this work in reducing both moisture content and deconsolidation. However, vacuum oven storage did not completely eliminate deconsolidation, as some moisture remained. Moreover, drying in a vacuum oven is very time and energy consuming, as it can take months for a laminate to dry completely. A short treatment at high temperature in a convection oven is more time and energy efficient and proved even more effective. A temperature well above $T_{\mathrm{g}}$ seems to be essential for rapid drying, as a treatment of $3 \mathrm{~h}$ at $150^{\circ} \mathrm{C}$ did not influence deconsolidation significantly. A treatment of $3 \mathrm{~h}$ at $250{ }^{\circ} \mathrm{C}$ worked particularly well for the $\mathrm{C} / \mathrm{PEEK}$ material used in this work.

\subsection{Influence of blank consolidation quality}

Similar to the press-consolidated specimen, the net deconsolidation of the AFP specimen can be found by subtracting the thermal expansion from the TMA curve, as is shown in Fig. 13. This assumes that thermal expansion of the press-consolidated and AFP specimens are identical, although a slight difference can be observed in Fig. 9. Besides the initial deconsolidation peak and some subsequent sagging, the curve shows a small second peak due to a difference in shrinkage during cooling between the press-consolidated and AFP specimen. The net thickness increase of the AFP specimen clearly shows a different trend than the press-consolidated specimen, indicating that moisture may not be the main deconsolidation mechanism here.

The different response of the AFP specimens to the drying treatments compared to the press-consolidated specimens can be explained partially by the initial state of the laminates. Interlaminar voids have remained in the laminate due to the rapid lay-up. These voids form a void channel network [34,35], and allow for the early release of moisture, as can be seen in Fig. 11(c), and prevent pressure build-up. Due to the lack of pressure build-up, the AFP specimen does not show the same sudden expansion in the TMA results as the press-consolidated specimen when crossing the melting temperature. The presence of a void channel network could also explain why additional drying treatments have no significant effect on deconsolidation of the AFP specimens. For the same reason it is also assumed that the additional release of air that was observed during the RGA of the AFP specimens does not contribute significantly to the thickness increase.

The imperfect interlaminar bonding that results from rapid lay-up prevents pressure build-up and void growth by moisture expansion. This means that deconsolidation due to moisture expansion can be influenced by the blank consolidation quality or, more specifically, the degree of interlaminar bonding. This could serve as an advantage of blanks produced by rapid AFP.

\subsection{Influence of prepreg and blank consolidation process}

Deconsolidation of the AFP specimens does not seem to be influenced by moisture content and the specimens show a very different deconsolidated state compared to the press-consolidated specimens. This suggests that deconsolidation of the AFP laminates is governed by a different mechanism.

To further investigate the governing mechanism, Fig. 14(a)-(c) show cross-sectional micrographs of individual prepreg plies before deconsolidation, after deconsolidation, and after deconsolidation with heat treatment of $3 \mathrm{~h}$ at $250^{\circ} \mathrm{C}$. Additionally, Fig. 14(d) shows a deconsolidated prepreg ply which has been press-consolidated prior to deconsolidation. These micrographs show that the heat treatment did not affect deconsolidation behavior of the prepreg, as also was the case for the AFP specimens. Moreover, the deconsolidated prepreg shows a cross-section similar to the AFP specimen in Fig. 8(b). Similar out-ofplane ply waviness was also observed. Contrarily, the press-consolidated prepreg does not show this ply deconsolidation, but rather a more intact ply, as was found for the press-consolidated laminates in Fig. 6.

Based on the previous observations, the main cause of deconsolidation of the AFP blanks seems to lie in the prepreg and is neither significantly affected by the current AFP process, nor by a heat treatment, while this cause is eliminated by the press consolidation process.

Although not further proven within the scope of this work, it is suggested that the driving force for deconsolidation of the prepreg and AFP blanks is related to frozen-in fiber stresses within the plies. These stresses have most likely been introduced during the prepreg production process, for example due to tensioning, compressing or bending of 


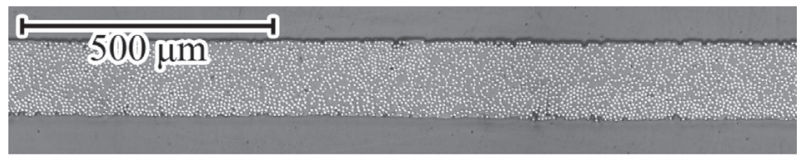

(a) As-received

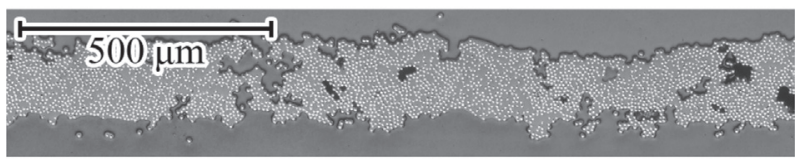

(b) As-received, deconsolidated

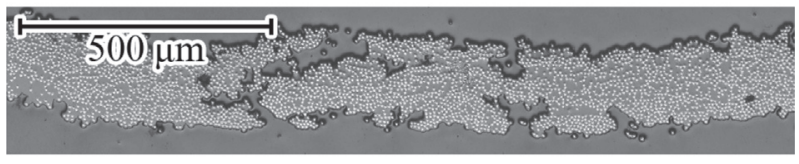

(c) Heat treatment (HT-3H@250C), deconsolidated

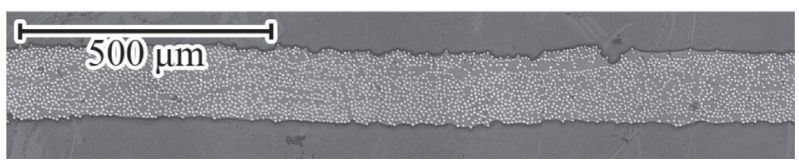

(d) Press-consolidated, deconsolidated

Fig. 14. Micrographs of cross-sections of prepreg (a) before and (b,c,d) after deconsolidation.

individual fibers or small fiber bundles, and are frozen in during solidification of the matrix. Upon remelting, the stresses in these fibers are relieved by allowing deformation of the fibers into a lower stress state. This stress relieve, possibly in combination with the poor interlaminar bonding that was achieved during rapid lay-up, would explain the deconsolidation of the individual plies and out-of-plane waviness after deconsolidation. It would also explain why annealing the matrix does not change the deconsolidation behavior, as fiber mobility is very limited at the annealing temperature. Apparently the fiber stresses are also relieved during press consolidation, while they are not during rapid AFP. This could be explained by the fact that press consolidation gives the fibers the time to settle in a more favorable state by keeping the entire laminate above $T_{\mathrm{m}}$ over a period of $30 \mathrm{~min}$. This resettling might not happen during the rapid AFP process, where the time spend above $T_{\mathrm{m}}$ is only $0.1 \mathrm{~s}$ and heating is very localized, although this may depend on the process settings used. This is supported by Fig. 11(b), which shows that deconsolidation of the AFP specimen takes about $30 \mathrm{~s}$. The fact that press consolidation relieves the fiber stresses is surprising, as press consolidation has often been found to be the origin of deconsolidation by elastic energy stored in the fiber bed [15,17-23], although it is also known that the effect is less pronounced for unidirectional prepreg [24]. Although some evidence has been provided that points toward the role of frozen-in fiber stresses as source of deconsolidation for the used prepreg and AFP blanks, more research is required to confirm this and investigate the influence of the AFP process by including thermal analysis.

The deconsolidation behavior can be highly prepreg specific, as was observed by the authors in previous work [36]. This demonstrates the large influence that the choice of prepreg (and the way it was manufactured) can have on deconsolidation behavior. Blanks made from a significantly deconsolidating prepreg may lead to poorly consolidated laminates after stamp forming, as the process may not be able to reestablish interlaminar bonding and eliminate all voids, although this is yet to be confirmed. Additionally, a loss of blank integrity due to deconsolidation may lead to undesired forming defects. Press consolidation was found to significantly alter the deconsolidation behavior and take away prepreg related causes for deconsolidation, which is a major benefit of press-consolidated blanks. An additional press-consolidation step after AFP seems to be required for the prepreg used in this work in order to avoid deconsolidation and ensure good consolidation quality after stamp forming. This additional processing step is undesired, as it takes away the benefit of rapid lay-up. However, the authors have experienced that using a prepreg which shows less deconsolidation also reduces blank deconsolidation, allowing omission of this extra step.

\section{Conclusions and recommendations}

Deconsolidation plays an important role in the stamp forming process, especially when blanks produced by rapid automated lay-up are used. The time available for reconsolidation is limited during stamp forming and deconsolidation should therefore be kept to a minimum. This requires proper characterization and control of the deconsolidation behavior.

The deconsolidation behavior of UD C/PEEK blanks was characterized experimentally in this work. Blanks produced by press consolidation and AFP, aimed at rapid lay-up, were considered in order to identify the influence of blank manufacturing process and consolidation quality on deconsolidation. The influence of moisture on deconsolidation was investigated during deconsolidation experiments in a convection oven. The moisture content was varied by applying various drying and wetting treatments prior to deconsolidation. Additional thermo-mechanical and residual gas analyses allowed for the coupled measurement of thickness increase due to deconsolidation and moisture release.

The results confirm that thermal expansion of dissolved moisture is the main deconsolidation mechanism for press-consolidated blanks, even for PEEK, which is known for its low moisture uptake. Deconsolidation due to moisture expansion can be eliminated by drying the blanks. A short high temperature heat treatment for $3 \mathrm{~h}$ at $250^{\circ} \mathrm{C}$ proved most effective for the C/PEEK used in this work.

For AFP blanks, deconsolidation was much more pronounced than for the press-consolidated blanks. However, dissolved moisture is not a major source of deconsolidation here. This is due to imperfect interlaminar bonding generated during rapid lay-up, which results in a void channel network that allows for the release of moisture without void formation. This is a benefit of AFP blanks with imperfect interlaminar bonding and demonstrates the influence of blank consolidation quality on deconsolidation.

It is suggested that deconsolidation in the AFP blanks used in this work is caused by another mechanism, which is related to frozen-in fiber stresses. This hypothesis is supported by the similar deconsolidation behavior of single prepreg plies compared to AFP blanks. Pressconsolidation seemed to eliminate the frozen-in stresses, demonstrating the influence the blank manufacturing process can have on deconsolidation. However, more in-depth analysis of the prepreg and the AFP process is required to confirm the role of frozen-in fiber stresses.

Blank deconsolidation may cause consolidation problems stamp forming and is therefore best avoided. This paper demonstrates that deconsolidation due to moisture expansion can be eliminated by drying blanks prior to processing, preferably during a high temperature heat treatment. Deconsolidation of AFP blanks due to internal prepreg stresses can be prevented by press consolidating blanks prior to stamp forming. However, this additional step is undesired, as it takes away the benefit of rapid lay-up. Therefore, using a prepreg that shows minimal deconsolidation is recommended for blank production with AFP.

\section{Acknowledgments}

This research was carried out under project number F11.4.15563 in 
the framework of the Partnership Program of the Materials innovation institute M2i (www.m2i.nl) and the Foundation of Fundamental Research on Matter (FOM) (www.fom.nl), which is part of the Netherlands Organisation for Scientific Research (www.nwo.nl). The authors gratefully acknowledge the financial and technical support from the industrial and academic members of the ThermoPlastic composites Research Center (TPRC), as well as the support funding from the Province of Overijssel for improving the regional knowledge position within the Technology Base Twente initiative.

\section{References}

[1] Ye L, Friedrich K, Kästel J, Mai Y-W. Consolidation of unidirectional CF/PEEK composites from commingled yarn prepreg. Compos Sci Technol 1995;54(4):349-58. https://doi.org/10.1016/0266-3538(95)00061-5.

[2] Jeong H. Effects of voids on the mechanical strength and ultrasonic attenuation of laminated composites. J Compos Mater 1997;31(3):276-92.

[3] Wakeman MD, Blanchard P, Månson J-AE. Void evolution during stamp-forming of thermoplastic composites. In: 15th international conference on composite materials (ICCM-15); 2005.

[4] Chambers A, Earl J, Squires C, Suhot M. The effect of voids on the flexural fatigue performance of unidirectional carbon fibre composites developed for wind turbine applications. Int J Fatigue 2006;28(10):1389-98. https://doi.org/10.1016/j. ijfatigue. 2006.02.033.

[5] Nikishkov Y, Guillaume S, Makeev A. Structural analysis of composites with porosity defects based on X-Ray Computed Tomography. J Compos Mater 2013:48(17):2131-44. https://doi.org/10.1177/0021998313494917.

[6] Liu X, Chen F. A review of void formation and its effects on the mechanical performance of carbon fiber reinforced plastic. Eng Trans 2016;64(1):33-51.

[7] Khan MA, Schledjewski R. Influencing factors for an online consolidating thermoplastic tape placement process. In: 17th international conference on composite materials; 2009.

[8] de Vries H. AFP technologies for high performance thermoplastics: characterization of mechanical performance and output rate. In: SETEC 11 06th international technical conference advanced composites, The integrated System; 2011. p. 293-303.

[9] Qureshi Z, Swait T, Scaife R, El-Dessouky H. In situ consolidation of thermoplastic prepreg tape using automated tape placement technology: potential and possibilities. Compos Part B: Eng 2014;66:255-67. https://doi.org/10.1016/j.compositesb. 2014.05.025.

[10] Comer A, Ray D, Obande W, Jones D, Lyons J, Rosca I, et al. Mechanical characterisation of carbon fibrePEEK manufactured by laser-assisted automated-tapeplacement and autoclave. Compos Part A: Appl Sci Manuf 2015;69:10-20. https:// doi.org/10.1016/j.compositesa.2014.10.003.

[11] Grouve W. Weld strength of laser-assisted tape-placed thermoplastic composites [Ph.D. thesis]. University of Twente; 2012.

[12] Slange TK, Warnet L, Grouve WJB, Akkerman R. Influence of preconsolidation on consolidation quality after stamp forming of C/PEEK composites. In: Chinesta F, Cueto E, Emmanuelle A-C, editors. ESAFORM 2016: proceedings of the 19th international ESAFORM conference on material forming. AIP conference proceedings; 2016.

[13] Lessard H, Lebrun G, Benkaddour A, Pham X-T. Influence of process parameters on the thermostamping of a $[0 / 90] 12$ carbon/polyether ether ketone laminate. Compos Part A: Appl Sci Manuf 2015;70:59-68. https://doi.org/10.1016/j. compositesa.2014.12.009.

[14] Donadei V, Wielandt M, Offringa A, Maffezzoli A. Effects of blank quality on press formed PEKK/carbon composite parts. In: SAMPE Europe 2017, Stuttgart; 2017.

[15] Shi H. Resistance welding of thermoplastic composites - process and performance
[Ph.D. thesis]. TU Delft; 2014

[16] Kok T, Grouve W, Warnet L, Akkerman R. Quantification of tape deconsolidation during laser assisted fiber placement. In: Hoa SV, editor. Automated composites manufacturing: third international symposium. DEStech Publications, Inc.; 2017.

[17] Gutowski T. Resin flow/fiber deformation model for composites. Sampe Quart 1985;16(4):58-64.

[18] Ye L, Lu M, Mai Y-W. Thermal de-consolidation of thermoplastic matrix composites - I. Growth of voids. Compos Sci Technol 2002;62(16):2121-30. https://doi.org/ 10.1016/S0266-3538(02)00144-6.

[19] Wolfrath J, Michaud V, Månson J-A. Deconsolidation in glass mat thermoplastic composites: analysis of the mechanisms. Compos Part A: Appl Sci Manuf 2005;36(12):1608-16. https://doi.org/10.1016/j.compositesa.2005.04.001.

[20] Ye L, Chen Z-R, Lu M, Hou M. De-consolidation and re-consolidation in CF/PPS thermoplastic matrix composites. Compos Part A: Appl Sci Manuf 2005;36(7):915-22.

[21] Gröschel C, Drummer D. The influence of moisture and laminate setup on the deconsolidation behavior or PA6/GF thermoplastic matrix composites. Int Polym Proc 2014;29(5):660-8.

[22] Wan Y, Takahashi J. Deconsolidation behavior of carbon fiber reinforced thermoplastics. J Reinf Plast Compos 2014;33(17):1613-24. https://doi.org/10.1177/ 0731684414538880.

[23] Brzeski M, Mitschang P. Deconsolidation and its interdependent mechanisms of fibre reinforced polypropylene. Polym Polym Compos 2015;23(8):515-24. https:// doi.org/10.1017/CBO9781107415324.004.

[24] Phillips R. Consolidation and solidification behavior of thermoplastic composites [Ph.D. thesis]; 1996.

[25] Leterrier Y, G'Sell C. Formation and elimination of voids during the processing of thermoplastic matrix composites. Polym Compos 1994;15(2):101-5.

[26] Roychowdhury S, Gillespie J, Advani S. Volatile-induced void formation in amorphous thermoplastic polymeric materials: I. Modeling and parametric studies. J Compos Mater 2001;35(4):340-66. https://doi.org/10.1177/ 002199801772662208.

[27] Guglhoer T, Sause M. The influence of moisture on the deconsolidation behaviour of carbon fiber reinforced PA-6 laminates. In: 17th international conference on composite materials; 2016.

[28] Henninger F, Ye L, Friedrich K. Deconsolidation behavior of glass fibre-polyamide 12 composite sheet material during post-processing. Plast Rubber Compos Process Appl 1998;27(6):287-92.

[29] Ten Cate Advanced Composites, Product Datasheet Cetex TC1200 PEEK Resin System; 2013.

[30] Grayson M, Wolf C. The solubility and diffusion of water in Poly(Aryl-Ether-EtherKetone) (PEEK). J Polym Sci : Part B: Polym Phys 1987;25:31-41.

[31] Wang Q, Springer GS. Moisture absorption and fracture toughness of PEEK polymer and graphite fiber reinforced PEEK. J Compos Mater 1998;23.

[32] Chen-Chi MM, Shih-Wen Y. Environmental effects on the water absorption and mechanical properties of carbon fiber reinforced PPS and PEEK. Compos Part II. Polym Eng Sci 1991;31(1):34-9. https://doi.org/10.1017/CBO9781107415324. 004 .

[33] Unger WJ, Hansen JS. The effect of cooling rate and annealing on residual stress development in graphite fibre reinforced PEEK laminates. J Compos 1993;27(2):108-37.

[34] Hernández S, Sket F, González C, LLorca J. Optimization of curing cycle in carbon fiber-reinforced laminates: void distribution and mechanical properties. Compos Sci Technol 2013;85:73-82. https://doi.org/10.1016/j.compscitech.2013.06.005.

[35] Schaefer P, Guglhoer T, Sause M, Drechsler K. Development of intimate contact during processing of carbon fiber reinforced Polyamide- 6 tapes. J Reinf Plast Compos 2017;36(8):593-607. https://doi.org/10.1177/0731684416687041.

[36] Slange TK, Warnet LL, Grouve WJB, Akkerman R. Influence of prepreg characteristics on stamp consolidation. In: ESAFORM 2017: proceedings of the 20th international ESAFORM conference on material forming. AIP conference proceedings; 2017. 